\title{
Improvement of the Quality of Brazilian Conilon through Wet Processing: A Sensorial Perspective
}

\author{
Lucas Louzada Pereira1 ${ }^{*}$, Aldemar Polonini Moreli1 ${ }^{1}$, Tais Rizzo Moreira ${ }^{2}$, \\ Carla Schwengber Ten Caten ${ }^{3}$, João Paulo Pereira Marcate ${ }^{1}$, \\ Danieli Grancieri Debona1, Rogério Carvalho Guarçoni4
}

\begin{abstract}
${ }^{1}$ Federal Institute of Education Science and Technology of Espirito Santo, Venda Nova do Imigrante Campus, Coffee Analysis and Research Laboratory-LAPC, Venda Nova do Imigrante, Brazil

${ }^{2}$ Federal University of Espírito Santo, Center for Agrarian Sciences and Engineering, Jerônimo Monteiro, Brazil

${ }^{3}$ Federal University of Rio Grande do Sul, Department of Production and Transportation Engineering, Porto Alegre, Brazil

${ }^{4}$ Capixaba Institute for Technical Assistance, Research and Extension-INCAPER, Department of Statistics, Domingos Martins, Brazil

Email: *lucasloza da@hotmail.com
\end{abstract}

How to cite this paper: Pereira, L.L., Moreli, A.P., Moreira, T.R., Caten, C.S.T., Marcate, J.P.P., Debona, D.G. and Guarçoni, R.C. (2019) Improvement of the Quality of Brazilian Conilon through Wet Processing: A Sensorial Perspective. Agricultural Sciences, 10, 395-411.

https://doi.org/10.4236/as.2019.103032

Received: January 29, 2019

Accepted: March 24, 2019

Published: March 27, 2019

Copyright $\odot 2019$ by author(s) and Scientific Research Publishing Inc. This work is licensed under the Creative Commons Attribution-NonCommercial International License (CC BY-NC 4.0).

http://creativecommons.org/licenses/by-nc/4.0/ (c) (i) (8) Open Access

\begin{abstract}
Conilon coffee represents almost $20 \%$ of all coffee production in the Brazilian territory; however, it is inexpressive in relation to the sensory quality when compared to Arabica coffee. It is noteworthy that the coffee from the species Coffea canephora PIERRE has a denser sensorial profile, is less sweet, less acidic and with strong pronunciation of the body at the time of tasting. This study has unprecedentedly applied the use of starter cultures (yeast) to optimize and modify the metabolic pathways and consequently the sensorial quality perceived by Q-graders. The experiments were conducted in a randomized block design with five replicates, in the $3 \times 4$ factorial scheme, with three fermentation times-24, 48 and 72 hours and four wet processing tests-Washed, Yeast fermentation, Fully washed without yeast and Fully washed with yeast. The sensorial results indicate a new perspective for the application of wet processing with starter cultures for Conilon coffee. They indicate gains in sensory scale, opening a new phase of studies on spontaneous and induced fermentation for Conilon coffee in Brazil and worldwide.
\end{abstract}

\section{Keywords}

Spontaneous Fermentation, Induced Fermentation, Sensory Routes, Conilon Coffee, Q-Graders, Sensory Aspects 


\section{Introduction}

Coffee is an important product for the Brazilian and world economies, Brazil being the largest producer and exporter of coffee in the world, which has in its productive composition two species of economic importance, Coffea arabica (Arabica coffee) and Coffea canephora (Conilon). Arabica coffee accounts for $81 \%$ of the cultivated area in the country and the Conilon for 19\% [1]. According to data from the US Department of Agriculture, the world consumes approximately 9 million tonnes of coffee per year [2].

Conilon coffee has sensory characteristics that normally present neutrality as to the sweetness and acidity; it has a remarkable aroma of roasted cereals and it stands out for the more pronounced body than Arabica coffee. Therefore, it is used as raw material in the solubilization industry and as a component in blends formulation with Arabica coffee [3].

In the case of coffee, the final quality of the product that is offered to the consumer is determined by the sensorial analysis, or popularly known as cup-tasting, done by tasters using personal opinion and tasting experience accumulated over the years [4] [5]. This task is often complex because the Q-Grader ${ }^{1}$ should be able to balance and define the sensory routes that best fit the reality of the consumer market that the coffee will be destined for, because the nuances of flavor and aroma are what make the evaluation of coffees a complex task [6]. In addition, during the roasting process, more than 800 aromatic compounds can be observed [6] [7].

The consumer preferences for a given coffee, or even for the method of preparation, can be influenced by a number of factors, such as culture, lifestyle, social and work environment, daily habits, financial aspects, and flavor [8].

In this range of sensory complexity and subjective factors such as the quality of a food product, many consumers stay away from discussions about the qualitative composition of a product that is offered in the global market, or even know little about the differences among varieties that are most consumed in the world. In the case of Coffea canephora PIERRE, it is known that the sensorial differences of preferences are distance among the coffees from the Arabica group.

The final quality of the coffee is related to the chemical constituents of the roasted grains, due to the wide chemical interaction that occurs during the roasting stages [3]. In the chemical perspective it is already known that the rates of caffeine, chlorogenic acids and reducing sugars are different according to the genetics and the groups, Arabica versus Conilon, and these differences are described by [9] [10] [11] [12] [13].

From the sensory perspective, it is known that coffee by the species Coffea arabica L. usually receives better notes on taste, aroma, sweetness and body than coffees from warmer regions [14]. This factor has been associated to the fact that high temperatures prevent the translocation of some chemical compounds to the ${ }^{1}$ Q-Grader: Q-Graders are qualified, controlled, and professionally trained coffee tasters at the Coffee Quality Institute (CQI). 
fruits [15] [16], thus being able to constitute a natural terroir ${ }^{2}$ of these micro-regions. These factors are widely discussed among researchers who study the behavior of these variables among Arabica coffee. In the case of the Coffea canephora PIERRE culture, these factors are beginning to be observed as possible quality indicators.

A new perspective on the production of specialty coffees emerges as an alternative to reduce such genetic, climatic and technological disparities. More recently, it has been argued that the effects of microorganisms present in processing and post-harvest, such as Debaryomyces, Pichia, Candida and Saccharomyces Kluyveri e S. Ceverisiae [17] [18]; filamentous fungi, such as Aspergillus, Penicillium and Fusarium e Trichoderma; bacteria, for example Lactobacillus, Bacillus, Arthrobacter, Acinetobacter and Klebsiella e Weissella [19] [20] [21] [22] [23]. Their fermentation capabilities can generate new opportunities for optimizing coffee quality. New perspectives emerged with the aim of potentiating the coffee quality curve through induced fermentation [24].

In this way, this study proposed to understand the impact of the introduction of wet processing technologies, which were commonly used in Arabica coffee, to evaluate the efficacy on the improvement of Conilon coffee quality-Coffeea canephora PIERRE.

From these facts observed and presented, the scientific hypothesis of this study is formulated: could it be possible to modify the chemical composition and consequently alter the sensorial perception of Conilon coffee through the spontaneous and induced fermentation techniques, thus altering the sensory routes?

This research presents in an unprecedented way how the quality of Coffea canephora PIERRE species can be optimized from the perspective of wet processing, observing the conditioning factors of the sensorial analysis in consonance with infrared analysis, approaching the sensorial routes perceived by Q-Graders, and proposing to demonstrate how the fermentation induced with yeast cultures is able to create metabolic routes that are capable of proposing improvements to the Conilon coffee produced in Brazil.

\section{Material and Methods}

\subsection{Sample Preparation: Wet Processing}

The raw materials selected for the experiments were composed of coffees of the species Coffea canephora PIERRE, from the Conilon variety Vitória were selected in different places in Espírito Santo.

The coffees were processed according to the same specifications described as follows: coffee pulp, husk from peeling, water and industrialized yeast (Saccharomyces cerevisiae sp.). Fifteen kilos of coffee were harvested per experimental plot in both experiments, presenting $95 \%$ of ripe fruits. After harvesting, the fruits were processed according to established processes.

${ }^{2}$ References that identify a good as originating in the territory of a country or a region, or locality in that territory, where a particular quality, reputation or other characteristic of the good is essentially attributable to its geographical origin. 
Of the four proposed methods, wort was prepared from the patent process BR1020160040531, with industrialized yeast culture, the brand Fleischmann (Saccharomyces cerevisiae sp.) and coffee husk. All experiments were conducted inside the Fermentation Laboratory of the Coffee Analysis and Research Laboratory-LAPC.

The four methods had the following processes:

1) Treatment 1: fermentation wort with water (Washed), $10 \mathrm{~kg}$ of peeled coffee cherries (pulp), $5 \mathrm{~kg}$ of husk and 5 liters of water;

2) Treatment 2: fermentation wort with yeast starter culture (Saccharomyces cerevisiae sp.-Yeast fermentation), $1 \%\left(\mathrm{p} / \mathrm{v}^{3}\right)$ of wort, $10 \mathrm{~kg}$ of peeled coffee cherries (pulp) $5 \mathrm{~kg}$ of husk, 5 liters of water;

3) Treatment 3: dry fermentation wort (Fully washed without yeast), $10 \mathrm{~kg}$ of peeled coffee cherries (pulp) and $5 \mathrm{~kg}$ of husk, without additional water to the process;

4) Treatment 4: dry fermentation wort with yeast (Fully washed with yeast), fermentation wort with yeast starter culture (Saccharomyces cerevisiae $s p$.), in the proportion of $1 \%(\mathrm{p} / \mathrm{v})$ of the wort, $10 \mathrm{~kg}$ of peeled coffee cherries (pulp), 5 $\mathrm{kg}$ of husk, without addition of water.

To perform the experiments, worts 1 and 2 received water to the processing at $38^{\circ} \mathrm{C}[25]$ and remained immersed in fermentation tanks in the processing laboratory of the Federal Institute of Espírito Santo (IFES), Campus Venda Nova do Imigrante, for 24, 48 and 72 hours. Worts 3 and 4 received only husk originated from the wet processing and remained in the process of fermentation for 24, 48 and 72 hours. Wort 3 received no addition of external microorganisms.

After the fermentation period, worts 1, 2, 3 and 4 were washed and taken to dry in a suspended and covered yard [26].

\subsection{Preparation of the Samples for Sensory Analysis}

After the resting period of the samples, 45 days, coffees were classified by type and sieve [27]. For the roasting process were admitted coffees with $100 \%$ from sieve 15 up.

The samples were prepared in the coffee sensory analysis laboratory of the Federal Institute of Espírito Santo, Venda Nova do Imigrante campus, respecting the methodology of the Uganda Coffee Development Authority [27]. Roasting was conducted using the Laboratto TGP-2 roaster with the Agtron-SCA disk set. The roasting point of these samples was between the colors determined by disks \#65 and \#55 for specialty coffees [28].

Roasting was executed 24 hours in advance and grinding respected the time of 8 hours of rest after roasting. All samples were roasted for 9 to 10 minutes and, after roasting and cooling, the samples remained sealed, according to the methodology of sensorial analysis established by the UCDA [27].

The coffee samples were ground with Bunn G3 electric grinder, in the me-

${ }_{3}^{3}$ Part by volume (quantity of microorganism as a function of the wort). 
dium to coarse particle size range. Five cups of each batch of coffee were prepared for cupping. The optimal ratio of $8.25 \mathrm{~g}$ of ground coffee per $150 \mathrm{ml}$ of water was adopted, as this conforms to the mid-point of the balance chart, optimal to achieve the Golden Cup [29]. The infusion was performed after the water reached $92^{\circ} \mathrm{C}-95^{\circ} \mathrm{C}$. The Q-Graders began the evaluation when the temperature of the cups reached $55^{\circ} \mathrm{C}$, respecting the time of 4 minutes from the infusion to the evaluation.

\subsection{Sensory Analysis by the UCDA Method}

The sensory analysis of the coffees was carried out by a panel of 6 (six) cuppers, all with Q-Grader ${ }^{4}$ certification, aiming at reducing the subjectivity of the analysis [30] [31].

\subsection{Experimental Design}

The experiment was conducted in a randomized block design with five replicates, in a $3 \times 4$ factorial scheme, with three fermentation times (24, 48 and 72 hours) and four wet-processing tests: Washed, Yeast fermentation, Fully washed without yeast and Fully washed with yeast.

For the statistical analysis of the sensory data, analysis of variance were performed, the means were compared by the Tukey test, the regression models tested using the $\mathrm{F}$ tests and the estimators using the $\mathrm{t}$ test. In order to group the treatments, we used canonical variables analysis, through visual exams in graphic dispersions, being recommended the scores of the first two canonical variables, which explain more than $80 \%$ of the total available variation. The software Genes was used in the statistical analysis.

\section{Results and Discussion}

The results are distributed in two-panel presentation, so initially the sensory results are addressed and sequentially the data from the infrared analysis. Thereafter, we proposed a joint discussion of the results found.

Table 1 presents the sensory results where the attributes that are evaluated in the Uganda Coffee Development Authority protocol are available [27].

No significant functional relationships were observed between fragrance, flavor, aftertaste, salt/acid aspect ratio, bitter/sweet aspect ratio, mouthfeel, global score and the fermentation time for all four processes.

The results of Table 1 present the sensory results for the treatments Washed ${ }^{1}$, Yeast Fermentation ${ }^{2}$, Fully washed without yeast ${ }^{3}$ and Fully washed with yeast ${ }^{4}$, within each fermentation time-24, 48 and 72 hours respectively. The results were discussed using the numerical label of each processing, to facilitate the understanding of the analysis.

${ }^{4}$ Q-Graders, are skilled and credible coffee cuppers certified by the Coffee Quality Institute (CQI). 
Table 1. Sensorial characteristics of time to fermentation processing. Sensory functional means evaluated in three fermentation times and four processes.

\begin{tabular}{|c|c|c|c|c|c|c|c|c|}
\hline \multirow{3}{*}{$\frac{\text { Sensorial variable }}{\text { Processing }}$} & \multicolumn{6}{|c|}{ Fragrance/Aroma } & & \\
\hline & \multicolumn{6}{|c|}{ Time to fermentation processing $(\mathrm{h})$} & \multirow{2}{*}{\multicolumn{2}{|c|}{ Média }} \\
\hline & \multicolumn{2}{|c|}{24} & \multicolumn{2}{|c|}{48} & \multicolumn{2}{|c|}{72} & & \\
\hline 1) Washed & 7.55 & $\mathrm{ab}$ & 7.38 & $\mathrm{~b}$ & 7.35 & $\mathrm{~b}$ & 7.43 & $\mathrm{bc}$ \\
\hline 2) Yeast fermentation & 7.44 & $\mathrm{~b}$ & 7.43 & $\mathrm{~b}$ & 7.61 & $\mathrm{a}$ & 7.49 & $\mathrm{~b}$ \\
\hline 3) Fully washed without yeast & 7.44 & $\mathrm{~b}$ & 7.34 & $\mathrm{~b}$ & 7.38 & $\mathrm{~b}$ & 7.39 & c \\
\hline 4) Fully washed with yeast & 7.69 & $\mathrm{a}$ & 7.63 & $\mathrm{a}$ & 7.61 & $\mathrm{a}$ & 7.64 & a \\
\hline Average & 7.53 & & 7.45 & & 7.49 & & & \\
\hline Sensory variable & \multicolumn{6}{|c|}{ Flavor } & & \\
\hline \multirow{2}{*}{ Processing } & \multicolumn{6}{|c|}{ Fermentation Time (h) } & \multirow{2}{*}{\multicolumn{2}{|c|}{ Average }} \\
\hline & \multicolumn{2}{|c|}{24} & \multicolumn{2}{|c|}{48} & \multicolumn{2}{|c|}{72} & & \\
\hline 1) Washed & 7.63 & $\mathrm{ab}$ & 7.43 & $\mathrm{a}$ & 7.37 & $\mathrm{bc}$ & 7.48 & $\mathrm{~b}$ \\
\hline 2) Yeast fermentation & 7.54 & $\mathrm{~b}$ & 7.45 & $\mathrm{a}$ & 7.64 & $\mathrm{a}$ & 7.54 & $\mathrm{ab}$ \\
\hline 3) Fully washed without yeast & 7.54 & $\mathrm{~b}$ & 7.34 & $\mathrm{a}$ & 7.34 & c & 7.41 & $\mathrm{~b}$ \\
\hline 4) Fully washed with yeast & 7.84 & $\mathrm{a}$ & 7.53 & $\mathrm{a}$ & 7.60 & $\mathrm{ab}$ & 7.66 & a \\
\hline Average & 7.64 & & 7.44 & & 7.49 & & & \\
\hline Sensory variable & \multicolumn{6}{|c|}{ Aftertaste } & & \\
\hline \multirow{2}{*}{ Processing } & \multicolumn{6}{|c|}{ Fermentation Time (h) } & \multirow{2}{*}{\multicolumn{2}{|c|}{ Average }} \\
\hline & \multicolumn{2}{|c|}{24} & \multicolumn{2}{|c|}{48} & \multicolumn{2}{|c|}{72} & & \\
\hline 1) Washed & 7.40 & $\mathrm{a}$ & 7.25 & $\mathrm{a}$ & 7.22 & $\mathrm{a}$ & 7.29 & $\mathrm{~b}$ \\
\hline 2) Yeast fermentation & 7.41 & $\mathrm{a}$ & 7.34 & $\mathrm{a}$ & 7.49 & $\mathrm{a}$ & 7.41 & $\mathrm{ab}$ \\
\hline 3) Fully washed without yeast & 7.45 & $\mathrm{a}$ & 7.19 & $\mathrm{a}$ & 7.19 & $\mathrm{a}$ & 7.28 & $\mathrm{~b}$ \\
\hline 4) Fully washed with yeast & 7.67 & $\mathrm{a}$ & 7.35 & $\mathrm{a}$ & 7.46 & $\mathrm{a}$ & 7.49 & a \\
\hline Average & 7.48 & & 7.28 & & 7.34 & & & \\
\hline Sensory variable & & & & & & & & \\
\hline \multirow{2}{*}{ Processing } & \multicolumn{6}{|c|}{ Fermentation Time (h) } & \multirow{2}{*}{\multicolumn{2}{|c|}{ Average }} \\
\hline & \multicolumn{2}{|c|}{24} & & & & & & \\
\hline 1) Washed & 7.48 & $\mathrm{a}$ & 7.42 & $\mathrm{ab}$ & 7.20 & $\mathrm{a}$ & 7.36 & $\mathrm{ab}$ \\
\hline 2) Yeast fermentation & 7.36 & $\mathrm{a}$ & 7.30 & $\mathrm{ab}$ & 7.45 & $\mathrm{a}$ & 7.37 & $\mathrm{ab}$ \\
\hline 3) Fully washed without yeast & 7.43 & $\mathrm{a}$ & 7.18 & $\mathrm{~b}$ & 7.25 & $\mathrm{a}$ & 7.29 & $\mathrm{~b}$ \\
\hline 4) Fully washed with yeast & 7.57 & $\mathrm{a}$ & 7.53 & $\mathrm{a}$ & 7.39 & $\mathrm{a}$ & 7.49 & a \\
\hline Average & 7.46 & & 7.36 & & 7.32 & & & \\
\hline Sensory variable & & & Bitte & weet & & & & \\
\hline Procscing & & & menta & Tin & & & & \\
\hline & & & & & & & & \\
\hline 1) Washed & 8.11 & $\mathrm{a}$ & 7.77 & $\mathrm{a}$ & 7.82 & $\mathrm{a}$ & 7.90 & a \\
\hline 2) -Yeast fermentation & 8.00 & $\mathrm{a}$ & 7.89 & $\mathrm{a}$ & 8.06 & $\mathrm{a}$ & 7.98 & a \\
\hline 3) Fully washed without yeast & 8.03 & $\mathrm{a}$ & 7.83 & $\mathrm{a}$ & 7.78 & $\mathrm{a}$ & 7.88 & a \\
\hline 4) Fully washed with yeast & 8.13 & $\mathrm{a}$ & 7.82 & $\mathrm{a}$ & 7.94 & $\mathrm{a}$ & 7.96 & a \\
\hline Average & 7.46 & & 7.36 & & 7.32 & & & \\
\hline
\end{tabular}




\section{Continued}

\begin{tabular}{|c|c|c|c|c|c|c|c|c|}
\hline Sensory variable & \multicolumn{6}{|c|}{ Mouthfeel } & & \\
\hline \multirow{2}{*}{ Processing } & \multicolumn{6}{|c|}{ Fermentation Time (h) } & \multirow{2}{*}{\multicolumn{2}{|c|}{ Average }} \\
\hline & \multicolumn{2}{|c|}{24} & \multicolumn{2}{|c|}{48} & \multicolumn{2}{|c|}{72} & & \\
\hline 1) Washed & 7.61 & $\mathrm{a}$ & 7.34 & $\mathrm{a}$ & 7.23 & $\mathrm{~b}$ & 7.39 & $\mathrm{a}$ \\
\hline 2) Yeast fermentation & 7.51 & $\mathrm{a}$ & 7.46 & $\mathrm{a}$ & 7.58 & $\mathrm{a}$ & 7.51 & a \\
\hline 3) Fully washed without yeast & 7.56 & $\mathrm{a}$ & 7.27 & $\mathrm{a}$ & 7.30 & $\mathrm{ab}$ & 7.38 & a \\
\hline 4) Fully washed with yeast & 7.69 & $\mathrm{a}$ & 7.38 & $\mathrm{a}$ & 7.56 & $\mathrm{a}$ & 7.54 & a \\
\hline Average & 7.59 & & 7.36 & & 7.42 & & & \\
\hline Sensory variable & \multicolumn{6}{|c|}{ Balance } & & \\
\hline \multirow{2}{*}{ Processing } & \multicolumn{6}{|c|}{ Fermentation Time (h) } & \multirow{2}{*}{\multicolumn{2}{|c|}{ Average }} \\
\hline & \multicolumn{2}{|c|}{24} & \multicolumn{2}{|c|}{48} & \multicolumn{2}{|c|}{72} & & \\
\hline 1) Washed & 7.48 & a & 7.35 & a & 7.19 & $\mathrm{~b}$ & 7.34 & $\mathrm{~b}$ \\
\hline 2) Yeast fermentation & 7.47 & $\mathrm{a}$ & 7.40 & a & 7.51 & $\mathrm{a}$ & 7.46 & $\mathrm{ab}$ \\
\hline 3) Fully washed without yeast & 7.48 & a & 7.28 & a & 7.25 & $\mathrm{~b}$ & 7.34 & $\mathrm{~b}$ \\
\hline 4) Fully washed with yeast & 7.60 & $\mathrm{a}$ & 7.37 & a & 7.53 & $\mathrm{a}$ & 7.50 & a \\
\hline Average & 7.50 & & 7.35 & & 7.37 & & & \\
\hline
\end{tabular}

Regression Model ${ }^{\star}$ and ${ }^{*}$ Significant at the $5 \%$ and $1 \%$ probability levels by the $\mathrm{t}$ and $\mathrm{F}$ tests, respectively.

\begin{tabular}{|c|c|c|c|c|c|c|c|c|}
\hline Sensory variable & \multicolumn{6}{|c|}{ Overall } & & \\
\hline \multirow{2}{*}{ Processing } & \multicolumn{6}{|c|}{ Fermentation Time (h) } & \multirow{2}{*}{\multicolumn{2}{|c|}{ Average }} \\
\hline & \multicolumn{2}{|c|}{24} & \multicolumn{2}{|c|}{48} & \multicolumn{2}{|c|}{72} & & \\
\hline 1) Washed & 7.49 & a & 7.36 & $\mathrm{a}$ & 7.22 & $\mathrm{c}$ & 7.36 & $\mathrm{~b}$ \\
\hline 2) Yeast fermentation & 7.49 & a & 7.37 & $\mathrm{a}$ & 7.58 & $\mathrm{a}$ & 7.48 & $\mathrm{ab}$ \\
\hline 3) Fully washed without yeast & 7.48 & a & 7.28 & $\mathrm{a}$ & 7.28 & bc & 7.34 & $\mathrm{~b}$ \\
\hline 4) Fully washed with yeast & 7.68 & a & 7.44 & $\mathrm{a}$ & 7.55 & $\mathrm{ab}$ & 7.56 & a \\
\hline Average & 7.54 & & 7.36 & & 7.40 & & & \\
\hline
\end{tabular}

Regression Model ${ }^{\star}$ and ${ }^{*}$ Significant at the $5 \%$ and $1 \%$ probability levels by the $\mathrm{t}$ and $\mathrm{F}$ tests, respectively.

\begin{tabular}{|c|c|c|c|c|c|c|c|c|}
\hline Sensory variable & \multicolumn{6}{|c|}{ Global Note } & & \\
\hline \multirow{2}{*}{ Processing } & \multicolumn{6}{|c|}{ Fermentation Time (h) } & \multirow{2}{*}{\multicolumn{2}{|c|}{ Average }} \\
\hline & \multicolumn{2}{|c|}{24} & \multicolumn{2}{|c|}{48} & \multicolumn{2}{|c|}{72} & & \\
\hline 1) Washed & 80.74 & $\mathrm{a}$ & 79.29 & a & 78.59 & $c$ & 79.54 & $\mathrm{~b}$ \\
\hline 2) Yeast fermentation & 80.22 & $\mathrm{a}$ & 79.63 & $\mathrm{a}$ & 80.91 & $\mathrm{a}$ & 80.25 & $\mathrm{ab}$ \\
\hline 3) Fully washed without yeast & 80.42 & $\mathrm{a}$ & 78.71 & $\mathrm{a}$ & 78.77 & $\mathrm{bc}$ & 79.30 & $\mathrm{~b}$ \\
\hline 4) Fully washed with yeast & 81.87 & $\mathrm{a}$ & 79.71 & $\mathrm{a}$ & 80.63 & $\mathrm{ab}$ & 80.74 & $\mathrm{a}$ \\
\hline Média & 80.81 & & 79.34 & & 79.73 & & & \\
\hline
\end{tabular}

Means followed by at least one letter vertically do not differ from each other by the Tukey test at $5 \%$ probability.

For the variable fragrance, at the time of 24 hours, treatments 1 and 4 did not present statistical differences among themselves. However, treatment 4 was superior to treatments 2 and 3 . At the time of 48 hours only treatment 4 is superior 
to the others and at the time of 72 hours treatments 2 and 4 differ from the others and present the best results respectively, based on the Tukey test at 5\% probability.

The observed alternations between the processes for the variable fragrance showed that the variations in the fermentation phase require more control. It was observed that method 4 presented the best results in the general average by the Tukey test at 5\% probability. Dry fermentation without yeast, treatment 3, showed the worst results but did not differentiate from treatment 1.

The flavor of coffee is surely one of the most complex sensory attributes to be defined and understood. This indicates that in longer roasting profiles a small variation in the roasting time may alter the coffee flavor profile, since different compounds can be produced more or less intensely [32].

Among the treatments applied at the 24-hour fermentation time, the results indicated that treatment 4 differed from treatments 2 and 3 but did not differ from treatment 1 at $5 \%$ of probability by Tukey's test. In addition, treatments 1 , 2, 3 and 4 did not show statistical difference between them, for the time of 48 hours. Treatments 2 and 4 did not present statistical difference between them at the time of 72 hours. Moreover, treatment 2 differed from treatments 1 and 3 at $5 \%$ probability by Tukey test.

In general means treatments 2 and 4 did not present statistical difference between them; however, treatment 2 showed better sensory results than treatments 1 and 3 . In relation to the general mean, treatment 4 had better results than treatments 1 and 3, but did not differentiate from treatment 2 . The effects of wet processing on the chemical and sensory changes of coffee are evident [33]. However, the authors conclude that, despite the wide variety of metabolites observed, it seems unlikely that any one of them will explain to a large extent its real impacts on the sensory structure of a coffee.

For the sensory variable aftertaste, the treatments did not present statistical difference by the Tukey test at 5\% probability at 24, 48 and 72-hour times. However, in general average, treatments 2 and 4 did not show statistical difference among themselves and treatment 4 was superior to treatments 1 and 3 . Once again treatment 4 stands out with one of the best sensorial results also considering the variables fragrance and flavor, even not differentiating from treatment 2 in which was also used yeast.

The aftertaste is an important evaluation feature, since it is usually the last coffee reading during the tasting session [29]. The aftertaste is defined as the persistence of taste, in other words, a characteristic perceived in sequence of the taste, which remains after the coffee is expelled from the mouth. If the aftertaste leaves sensation of short duration or even if it is unpleasant, a low score may be applied.

This variable has been little described in the scientific literature in the coffee area. It is known that chemically there is a relationship between food bitterness and aftertaste, due to the high load of tannic acid, also called tannin. Tannins are astringent; polyphenols bind, precipitate and shrink proteins, causing tannin as- 
tringency to manifest as a sensation of drought. This sensation is felt in the mouth after consumption of some wines, strong tea or unripened fruit [34].

Data from the variable acidity indicated that for the fermentation of 24 and 72 hours the treatments did not present statistical differences among themselves by the Tukey test at $5 \%$ of probability. However, at the fermentation time of 48 hours, treatment 4 was superior to treatment 3, but it did not differ from the other treatments by the Tukey test at $5 \%$ probability. The same behavior can be observed on the mean values for the variable acidity; treatment 4 once again stood out considering the variables fragrance and flavor, even though it did not differentiate statistically from treatments 1 and 2 for this variable.

The acidity in coffee has been the subject of several scientific controversies. According to [35], low quality coffee is associated with high acidity indexes, mainly due to the harmful fermentation. There is a tendency that when the acidity increases, the quality of the coffee decreases [36].

This suggests that the metabolic processes generated during the induced fermentation phase had a significant effect on the production of some compounds that confer a higher acidity load on coffee. However, these factors should be better studied, since the data of [37] suggest that the use of yeasts (Saccharomyces cerevisiae sp.) provided improvement of the acidity of the coffees corroborating in parts with the results found for this variable.

For the variable bitterness/sweetness the treatments did not present statistical differences in any of the proposed methods and in any of the fermentation times by the Tukey test at $5 \%$ probability. The same behavior was observed in the average of the results for the bitterness/sweetness variable. Although statistical difference was not observed, once again treatment 4 showed the best results in general considering the variables already discussed. It is necessary to emphasize that this variable is evaluated differently in relation to the coffee protocol of the Arabica group.

The body is a sensory perception of the weight of the drink on the tongue. Thus, the relationship of the coffee sensation on the palate may vary according to the nature of the weight. A high body score may also be perceived as a defect in some cases [38]. For the mouth-feel variable, the treatments did not present statistical differences for the 24 and 48-hour times. However, at the 72-hour time, treatments 2,3 and 4 did not present statistical differences among themselves at $5 \%$ probability by Tukey test and treatment 3 did not differ from treatment 1 . In the general average, the treatments did not present statistical differences.

The sensation of coffee in the sensorial analysis is relativized as a perception of coffee density in the palate. Q-Graders when evaluating the coffees tend to value the intensity of this density, but, in excess, it becomes aggressive to the palate. It was observed for this variable that treatment 4 also collaborates with the fragrance and flavor characteristics for better sensorial quality of the coffee.

For the variable balance, at the fermentation times of 24 and 48 hours, the treatments did not present statistical differences by the Tukey test at $5 \%$ proba- 
bility. However, for the 72-hour time, treatments 2 and 4 did not present statistical differences among themselves but were higher than the others at $5 \%$ probability. On average, treatment 4 presented the best sensory results, it differed from treatments 1 and 3, but it did not differ from treatment 2 at 5\% probability by the Tukey test.

A significant functional relationship was observed between balance and fermentation time for process $1, \mathrm{y}=7.62222-0.005902^{*} \times$ and $\mathrm{R}^{2}=0.9954^{* *}$, that is, balance decreases with the fermentation time. For the other processes, no significant functional relationships were observed between balance and fermentation time (Table 1).

This result gives an important indication about fermentation processes. The formation of the microbiota, the room's temperature and the $\mathrm{pH}$ of the wort may undergo changes, and modify the charge and the way the microorganisms act during the fermentation process [20].

The fruits of coffee, when processed, allow the emergence of a spontaneous or wild fermentation. The sugars and pectins present in the mucilage allow the growth of microorganisms, especially bacteria and yeasts. In this case, the non-specific selection of microorganisms in the spontaneous fermentation phase may lead to a disordered competition in the fermentation wort, for the coffee balance can be described by means of various chemical compounds that will interact during the processing and will manifest during the roasting. Sugar and amino acids are precursors to generate the caramelization process, triggered by the Maillard reaction, which will progress during roasting to produce brownish and bitter glycosylamine and melanoidins to give flavor to the coffee. Finally, this reaction tends to confer to the coffee beverage a balanced performance, taste and softness [39].

The sensorial results for this variable indicate a plausible behavior in the two treatments where yeasts were inoculated the results were more promising than the others, after 72 hours of induced fermentation. This indicates that the secondary metabolites may have altered the chemical composition of the fruits. The metabolic processes generated by the fermentation can confer some differentiated characteristics to the coffee, which can be explained by the direct connection with fermentation processes [40].

The penultimate sensory protocol variable, overall, is described by the SCA protocol [29] as an attribute that should reflect the integrated classification of the sample, as perceived by the individual panel. Thus, the Q-Graders exert a relative direct influence on the protocol of sensorial analysis, because at that moment the evaluator can extend his grades to differentiate more the coffees during the sensorial analysis. For the variable presented, the treatments did not present statistical differences at the times of 24 and 48 hours, however, in the 72-hour time, treatment 2 differed from treatment 1 and 3, but not from treatment 4 , at $5 \%$ probability by Tukey test. Treatments 1 and 3 did not show statistical differences between them. On average, treatment 4 was superior to treatments 1 and 3, but did not present statistical difference between treatment 2 by 
the Tukey test at $5 \%$ probability. Treatments 1,2 and 3 did not differ from each other.

A significant functional relationship was observed between the overall and fermentation time for processing $1, \mathrm{y}=7.63056-0.005729^{*} \times$ and $\mathrm{R}^{2}=0.9997^{* *}$, that is, the overall decreased with the fermentation time. For the other processes, no significant functional relationships were observed between overall and fermentation time in Table 1.

The behavior observed in the overall variable indicates the need for control in the spontaneous fermentation phase. In addition to bacteria, fungi and yeasts, more recently, the microbiota present in coffee fruits has received considerable attention regarding its diversity and potential contribution to positive attributes related to coffee quality [41]. From this arises the need to compare the internal microbiota of fruits from high regions with that of lower regions to understand the quality of fermentation. This factor may be associated to the fact that high temperatures prevent the translocation of chemical compounds to the fruits, opening a field for discussion about Conilon coffee microbiota [42].

As a conclusion of the sensorial analysis, the analysis protocol presents the variable global score. For this variable, the treatments did not present statistical differences between the fermentation times of 24 and 48 hours. The 72-hour fermentation time showed that treatments 2 and 4 did not differ statistically, although treatment 4 did not differentiate from treatment 3 by Tukey's test at $5 \%$ probability. In the general mean, treatment 4 presented a better overall score than treatments 1 and 3, but did not differ from treatment 2, a factor observed in all protocol variables, except for fragrance, in which treatment 4 was higher than 2 by Tukey's test at $5 \%$ probability.

\section{Multivariate Analysis of Sensory Processes}

Table 2 shows the eigenvalues and their respective simple and accumulated percentages, associated to the first two canonical variables, from which the scores of the 4 treatments were obtained. The graphical dispersion of the scores of the first two canonical variables is presented in Figure 1. The scores were plotted in a two-dimensional space, where the distance of these points is proportional to the degree of dissimilarity between the treatments.

In Figure 2, relative to the processing time of 24 hours, we observe the dispersion of the treatments based on the respective coordinates relative to the first two canonical variables, VC1 and VC2, in which treatment 1 (washed) formed the first group; treatments 2 and 3 (Yeast fermentation and Fully washed without yeast) formed the second group and treatment 4 (Fully washed with yeast) formed the third group. The two canonical variables absorbed 98.23\% (Table 2) of the variation in the original characteristics.

Then, at fermentation time of 48 hours, we observe the dispersion of the treatments based on the respective coordinates relative to the first two canonical variables, VC1 and VC2, in which the treatments: Washed, Yeast fermentation and Fully washed without yeast form a group and Fully washed with yeast form 


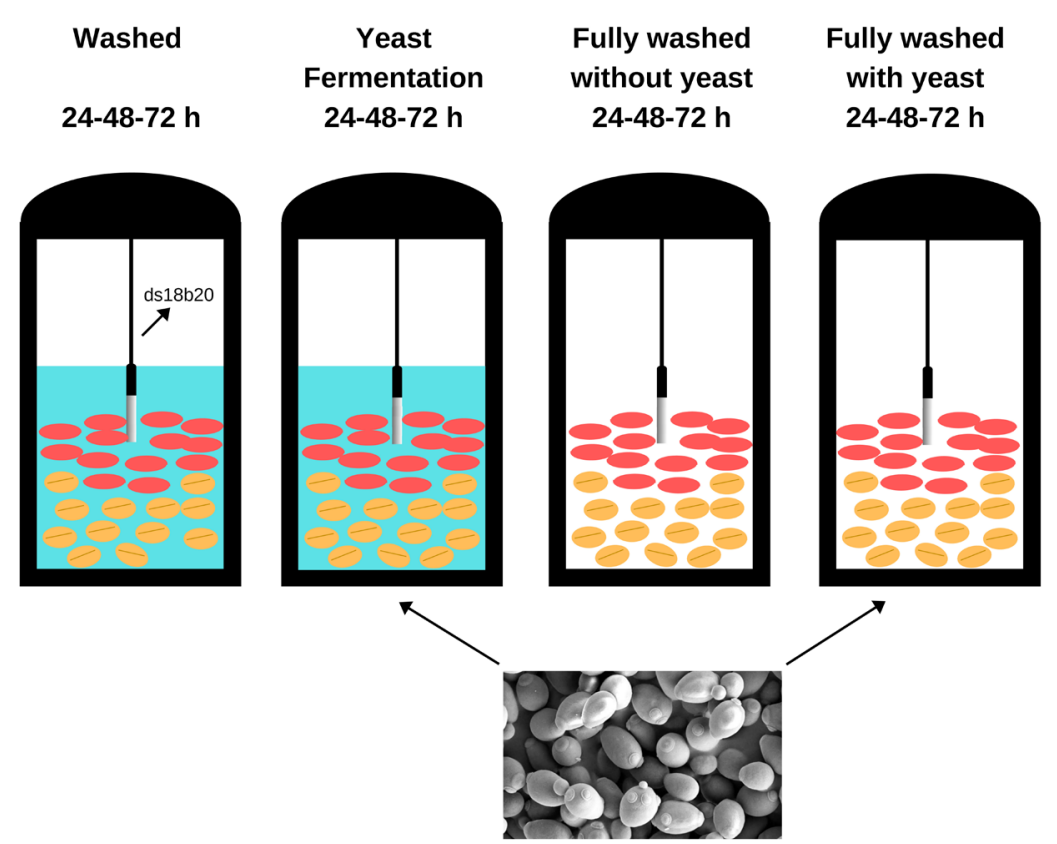

Saccharomyces cerevisiae

Figure 1. Scheme of fermentation tanks. Source: Elaboration of the authors.

Table 2. Main components and their respective eigenvalues and simple and cumulative percentages of the total variance.

\begin{tabular}{cccc}
\hline \multicolumn{4}{c}{ Eigenvalues for the fermentation time with 24 hours } \\
\hline Canonical variable & Eigenvalues & Simple percentage & $\begin{array}{c}\text { Accumulated } \\
\text { percentage }\end{array}$ \\
\hline VC1 & 7.8531148 & 80.0794574 & 80.0794574 \\
VC2 & 1.7800022 & 18.1509644 & 98.2304218 \\
\hline Canonical variable & Eigenvalues for the fermentation time with 48 hours & \\
\hline VC1 & Eigenvalues & Simple percentage & Accumulated \\
percentage
\end{tabular}

the other group. The two canonical variables absorbed $98.59 \%$ (Table 2) of the variation in the original characteristics.

The last fermentation time ( 72 hours) shows the dispersion of the treatments based on the respective coordinates relative to the first two canonical variables, VC1 and VC2, in which the treatments Washed and Fully washed without yeast form the first group, and Yeast fermentation and Fully washed with yeast form the second. The two canonical variables absorbed $99.25 \%$ (Table 2) of the varia- 
tion in the original characteristics.

Based on the dispersion of the groups observed in the set of images related to the VC's of Figure 2, it can be observed that the wet processing, when applied to the Conilon coffee, may undergo changes, and such changes may impact the quality perceived by the evaluators.

In the perspective of the metabolic routes that can be created through the wet process, according to [24] reinforce the discussion about the fermentation, considering that desirable attributes can be optimized during the wet processing.

The fermentation of the coffee occurs to solubilize polysaccharides that are present in the coffee pulp, consequently, during the fermentation, microorganisms will act in the degradation of the sugars present in the pulp, creating metabolic routes and differentiated sensorial patterns. These facts are proven with the observation of the groupings arranged in Figure 2.

These catabolic processes of oxidation of organic substances, especially sugars, which are transformed into energy and simpler compounds, such as ethanol, acetic acid, lactic acid and butyric acid, are caused by bacteria and yeasts, being the final result of fermentation dependent on the set of bacteria and yeasts present during these processing stages [43]. As previously reported, the use of Saccharomyces cerevisiae sp. provided improvements and qualitative gains to the coffees that were processed by this method, which can also be observed in Figure 1.

In addition to bacteria, fungi and yeasts, more recently, the endophytic microbiota present in coffee fruits has been receiving considerable attention regarding its diversity and potential contribution to positive attributes related to coffee quality [41]. From this arises the need to compare the internal microbiota of fruits from high regions with that of lower regions to understand the course of quality regarding the fermentation.

This interpretation corroborates the conclusions of [44], as for the authors further studies should be undertaken to strengthen the understanding of the impact of the microbiota on the quality of the coffee bean in order to provide robust data for the development of early commercial crops.

\section{Conclusions}

The use of yeast culture Saccharomyces cerevisiae sp. resulted in an improvement in the quality of the Conilon coffee in relation to the other processes, in all inoculation time; an improvement was reinforced for the fermentation method Fully washed with yeast, indicating potential for quality improvement through induced fermentation.

The regression models for the sensorial analysis indicated that the spontaneous water fermentation method-Washed-had a significant functional relationship between the attributes overall and balance to the fermentation time. That is, the quality of the coffees decays as the time of spontaneous fermentation increases. Thus, the need for a more in-depth study on the endophytic microbiota in Brazilian coffees Conilon is evident. 
Time to Fermentation - 24 hours

vc2

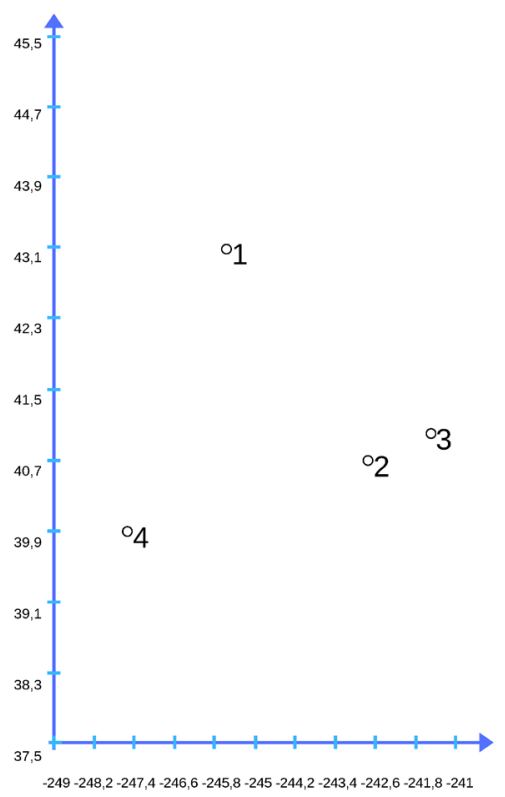

VC1

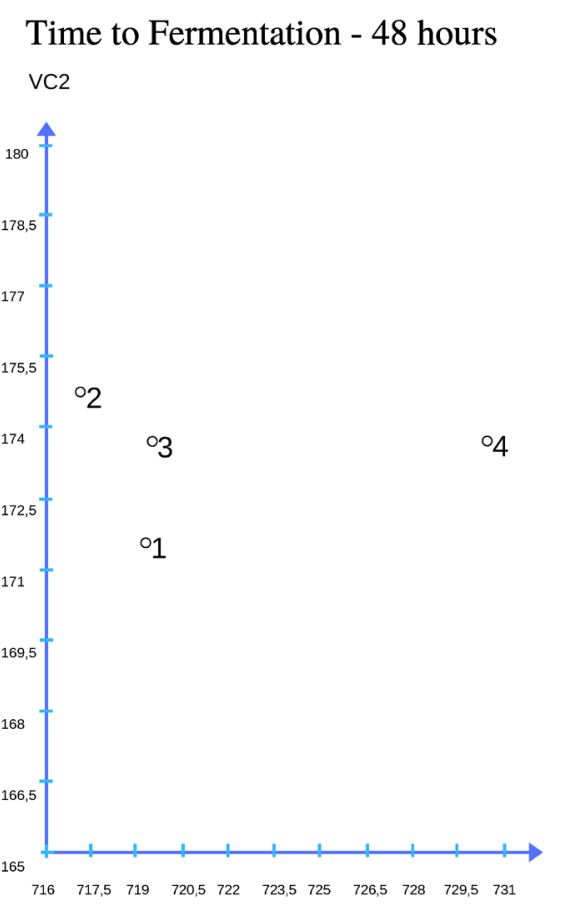

VC1
Time to Fermentation - 72 hours vc2

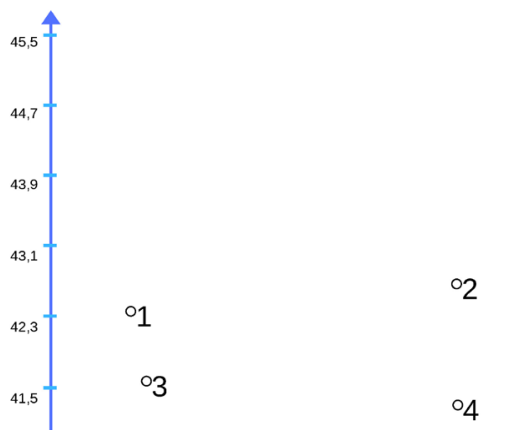

${ }^{\circ} 4$

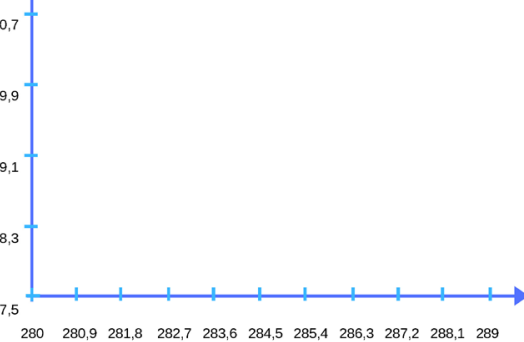

VC1

Figure 2. Scatter diagram of the first two canonical variables of the treatments: 1-Washed, 2-Yeast fermentation, 3-Fully washed without yeast and 4-Fully washed with yeast.

Based on the different types of processing and forms of use of the fermentations, it was possible to create sensorial routes for the Conilon coffee and to create a possibility of deepening the effects of the induced and spontaneous fermentation due to the different fermentation times, demonstrating new perspectives for the creation of sensory routes of Conilon coffee.

\section{Acknowledgements}

The authors thank the Federal Institute of Espírito Santo for supporting this research and also the translation and review of this article, as well as the Q-graders' participation, who dedicated themselves to the realization of this study and the Venturim Farm for making the materials available for field studies.

\section{Funding}

This research did not receive any specific grant from funding agencies in the public, commercial, or non-profit sectors.

\section{Conflicts of Interest}

The authors declare no conflicts of interest regarding the publication of this paper.

\section{References}

[1] Companhia Nacional de Abastecimento (CONAB) (2018) Acompanhamento da safra 
brasileira de café: Primeiro levantamento. 5-SAFRA 2018, 1-73.

[2] United States Department of Agriculture (USDA) (2018) Coffee: World Markets and Trade. Foreign Agricultural.

https://apps.fas.usda.gov/psdonline/circulars/coffee.pdf

[3] Ribeiro, B.B., et al. (2014) Avaliação química e sensorial de blends de Coffea canephora Pierre E Coffea arabica L. Coffee Science, 9, 178-186.

[4] Di Donfrancesco, B.D., Guzman, N.G. and Chambers, E. (2014) Comparison of Results from Cupping and Descriptive Sensory Analysis of Colombian Brewed Coffee. Journal of Sensory Studies, 29, 301-311. https://doi.org/10.1111/joss.12104

[5] Feria-Morales, A.M. (2002) Examining the Case of Green Coffee to Illustrate the Limitations of Grading Systems/Expert Tasters in Sensory Evaluation for Quality Control. Food Quality and Preference, 13, 355-367. https://doi.org/10.1016/S0950-3293(02)00028-9

[6] Bhumiratana, N., Adhikari, K. and Chambers, E. (2011) Evolution of Sensory Aroma Attributes from Coffee Beans to Brewed Coffee. LWT-Food Science and Technology, 44, 2185-2192. https://doi.org/10.1016/j.lwt.2011.07.001

[7] Alvarado, R.A. and Linnemann, A.R. (2010) The Predictive Value of a Small Consumer Panel for Coffee-Cupper Judgment. British Food Journal, 112, 1023-1032. https://doi.org/10.1108/00070701011074372

[8] Gloess, A.N., et al. (2013) Comparison of Nine Common Coffee Extraction Methods: Instrumental and Sensory Analysis. European Food Research and Technology, 236, 607-627. https://doi.org/10.1007/s00217-013-1917-x

[9] Alonso-Salces, R.M., et al. (2009) Botanical and Geographical Characterization of Green Coffee (Coffea arabica and Coffea canephora): Chemometric Evaluation of Phenolic and Methylxanthine Contents. Journal of Agricultural and Food Chemistry, 57, 4224-4235. https://doi.org/10.1021/jf8037117

[10] Liu, P., et al. (2012) Sensory Characteristics and Antioxidant Activities of Maillard Reaction Products from Soy Protein Hydrolysates with Different Molecular Weight Distribution. Food and Bioprocess Technology, 5, 1775-1789. https://doi.org/10.1007/s11947-010-0440-3

[11] Pereira, M.C., et al. (2010) Multivariate Analysis of Sensory Characteristics of Coffee Grains (Coffea arabica L.) in the Region of Upper Paranaíba. Acta Scientiarum. Agronomy, 32, 635-641. https://doi.org/10.4025/actasciagron.v32i4.4283

[12] Tfouni, S.A.V., et al. (2012) Effect of Roasting on Chlorogenic Acids, Caffeine and Polycyclic Aromatic Hydrocarbons Levels in Two Coffea Cultivars: Coffea arabica cv. Catuaí Amarelo IAC-62 and Coffea canephora cv. Apoatã IAC-2258. International Journal of Food Science and Technology, 47, 406-415. https://doi.org/10.1111/j.1365-2621.2011.02854.x

[13] Wei, F., et al. (2010) Complex Mixture Analysis of Organic Compounds in Green Coffee Bean Extract by Two-Dimensional NMR Spectroscopy. Magnetic Resonance in Chemistry, 48, 857-865. https://doi.org/10.1002/mrc.2678

[14] Taveira, J.H., et al. (2014) Potential Markers of Coffee Genotypes Grown in Different Brazilian Regions: A Metabolomics Approach. Food Research International, 61, 75-82. https://doi.org/10.1016/j.foodres.2014.02.048

[15] Bertrand, E., et al. (2006) Comparison of Bean Biochemical Composition and Beverage Quality of Arabica Hybrids Involving Sudanese-Ethiopian Origins with Traditional Varieties at Various Elevations in Central America. Tree Physiology, 26, 1239-1248. https://doi.org/10.1093/treephys/26.9.1239 
[16] Bosselmann, A.S., et al. (2009) The Influence of Shade Trees on Coffee Quality in Small Holder Coffee Agroforestry Systems in Southern Colombia. Agriculture, Ecosystems and Environment, 129, 253-260. https://doi.org/10.1016/j.agee.2008.09.004

[17] Pereira, G.V.M., et al. (2014) Isolation, Selection and Evaluation of Yeasts for Use in Fermentation of Coffee Beans by the Wet Process. International Journal of Food Microbiology, 188, 60-66. https://doi.org/10.1016/j.ijfoodmicro.2014.07.008

[18] Silva, C.F., Batista, L.R. and Schwan, R.F. (2008) Incidence and Distribution of Filamentous Fungi during Fermentation, Drying and Storage of Coffee (Coffea Arabica L.) Beans. Brazilian Journal of Microbiology, 39, 521-526. https://doi.org/10.1590/S1517-83822008000300022

[19] Evangelista, S.R., et al. (2014) Improvement of Coffee Beverage Quality by Using Selected Yeasts Strains during the Fermentation in Dry Process. Food Research International, 61, 183-195. https://doi.org/10.1111/joss.12104

[20] Evangelista, S.R., et al. (2014) Inoculation of Starter Cultures in a Semi-Dry Coffee (Coffea arabica) Fermentation Process. Food Microbiology, 44, 87-95. https://doi.org/10.1016/j.fm.2014.05.013

[21] Masoud, W. and Jespersen, L. (2006) Pectin Degrading Enzymes in Yeasts Involved in Fermentation of Coffea arabica in East Africa. International Journal of Food Microbiology, 110, 291-296. https://doi.org/10.1016/j.ijfoodmicro.2006.04.030

[22] Massawe, G.A. and Lifa, S.J. (2010) Yeasts and Lactic Acid Bacteria Coffee Fermentation Starter Cultures. International Journal of Postharvest Technology and Innovation, 2, 41-82. https://doi.org/10.1504/IJPTI.2010.038187

[23] Velmourougane, K. (2013) Impact of Natural Fermentation on Physicochemical, Microbiological and Cup Quality Characteristics of Arabica and Robusta Coffee. Proceedings of the National Academy of Sciences of the United States of America, 83, 233-239. https://doi.org/10.1007/s40011-012-0130-1

[24] Lee, L.W., et al. (2015) Coffee Fermentation and Flavor-An Intricate and Delicate Relationship. Food Chemistry, 185, 182-191. https://doi.org/10.1016/j.foodchem.2015.03.124

[25] Pereira, L.L. (2017) Novas abordagens para produção de cafés especiais a partir do processamento via-úmida. Ph.D. Dissertation, Federal University of Rio Grande do Sul, Rio Grande do Sul.

[26] Pereira, L.L., et al. (2018) Influence of Solar Radiation and Wet Processing on the Final Quality of Arabica Coffee. Journal of Food Quality, 2018, Article ID: 6408571. https://doi.org/10.1155/2018/6408571

[27] UCDA (2012) Uganda Coffee Development Authority. https://ugandacoffee.go.ug/sites/default/files/Resource_center/UCDA\%20Annual\% 20Report_2011-2012_0.pdf

[28] Specialty Coffee Association of American (2015) Protocols. SCAA. http://www.scaa.org/PDF/resources/cupping-protocols.pdf

[29] SCA (Specialty Coffee Association of American) (2015) Protocols. http://www.scaa.org/PDF/resources/cupping-protocols.pdf

[30] Pereira, L.L., et al. (2018) Propositions on the Optimal Number of Q-Graders and R-Graders. Journal of Food Quality, 2018, Article ID: 3285452. https://doi.org/10.1155/2018/3285452

[31] Pereira, L.L., et al. (2016) Tamanho Ótimo do Número de Provadores de Café com Uso do Protocolo SCAA. Great Size Number of Coffee Tasters with the Use of SCA Protocol, 19, 20-21. 
[32] Gloess, A.N., et al. (2014) Evidence of Different Flavour Formation Dynamics by Roasting Coffee from Different Origins: On-Line Analysis with PTR-ToF-MS. MASPEC-15125. International Journal of Mass Spectrometry, 365-366, 324-337. https://doi.org/10.1016/j.ijms.2014.02.010

[33] Joët, T., et al. (2010) Influence of Environmental Factors, Wet Processing and Their Interactions on the Biochemical Composition of Green Arabica Coffee Beans. Food Chemistry, 118, 693-701. https://doi.org/10.1016/j.foodchem.2009.05.048

[34] Ashok, P.K. and Upadhyaya, K. (2012) Tannins Are Astringent. Journal of Pharmacognosy and Phytochemistry, 1, 45-50.

[35] Mazzafera, P. (1999) Chemical Composition of Defective Coffee Beans. Food chemistry, 64, 547-554. https://doi.org/10.1016/S0308-8146(98)00167-8

[36] Franca, A.S., Mendonca, J.C.F. and Oliveira, S.D. (2005) Composition of Green and Roasted Coffees of Different Cup Qualities. LWT-Food Science and Technology, 38, 709-715. https://doi.org/10.1016/j.lwt.2004.08.014

[37] Ribeiro, L.R., et al. (2017) Controlled Fermentation of Semi-Dry Coffee (Coffea arabica) Using Starter Cultures: A Sensory Perspective. LWT-Food Science and Technology, 82, 32-38. https://doi.org/10.1016/j.lwt.2017.04.008

[38] Avelino, J., et al. (2005) Effects of Slope Exposure, Altitude and Yield on Coffee Quality in Two Altitude Terroirs of Costa Rica, Orosi and Santa María de Dota. Journal of the Science of Food and Agriculture, 85, 1869-1876. https://doi.org/10.1002/jsfa.2188

[39] Lin, C.C. (2010) Approach of Improving Coffee Industry in Taiwan-Promote Quality of Coffee Bean by Fermentation. The Journal of International Management Studies, 5, 154-159.

[40] Lee, L.W., et al. (2017) Modulation of the Volatile and Non-Volatile Profiles of Coffee Fermented with Yarrowia lipolytica: II. Roasted Coffee Liang. LWT-Food Science and Technology, 80, 32-42. https://doi.org/10.1016/j.lwt.2017.01.070

[41] Malta, M.R., et al. (2013) Alterações na qualidade do café submetido a diferentes formas de processamento e secagem. Reveng. Engenharia na agricultura, 21, 431-440. https://doi.org/10.13083/reveng.v21i5.450

[42] Damatta, F.M. (2004). Exploring Drought Tolerance in Coffee: A Physiological Approach with Some Insights for Plant Breeding. Brazilian Journal Plant Physiology, 16, 1-6. https://doi.org/10.1590/S1677-04202004000100001

[43] Puerta, G.I. (2000). Influencia de los granos de café cosechados verdes en la calidad física y organoléptica de la bebida. Cenicafé, 51, 136-150.

[44] De Bruyn, F., Zhang, S.J., Pothakos, V., et al. (2017) Exploring the Impacts of Postharvest Processing on the Microbiota and Metabolite Profiles during Green Coffee Bean Production. Applied and Environmental Microbiology, 83, 1-40. https://doi.org/10.1128/AEM.02398-16 